\title{
Design and Fabrication of Three-Dimensional Scaffolds for Tissue Engineering of Human Heart Valves
}

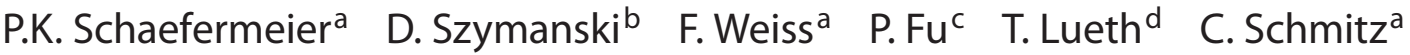

\author{
B.M. Meiser ${ }^{\text {a }}$ B. Reichart ${ }^{\text {a }} \quad$ R. Sodian ${ }^{a}$ \\ ${ }^{a}$ Department of Cardiac Surgery, Laboratory for Tissue Engineering, University Hospital of the \\ Ludwig-Maximilians-University, Munich, ${ }^{b}$ Surgical Robotics Laboratory, Department of Maxillofacial Surgery, \\ Charité University Medicine Berlin, Campus Virchow, and ' Department of Thoracic and Cardiovascular Surgery, \\ Laboratory for Tissue Engineering, Deutsches Herzzentrum Berlin, Berlin, and ${ }^{\mathrm{d}}$ Zentralinstitut für Medizintechnik, \\ Technical University Munich, Garching, Germany
}

\section{Key Words}

Heart valve $\cdot$ Prosthetic heart valve $\cdot$ Aortic valve $\cdot$ Tissue engineering $\cdot$ Polymeric scaffold $\cdot$ Sinus of Valsalva

\begin{abstract}
We developed a new fabrication technique for 3-dimensional scaffolds for tissue engineering of human heart valve tissue. A human aortic homograft was scanned with an X-ray computer tomograph. The data derived from the X-ray computed tomogram were processed by a computer-aided design program to reconstruct a human heart valve 3-dimensionally. Based on this stereolithographic model, a silicone valve model resembling a human aortic valve was generated. By taking advantage of the thermoplastic properties of polyglycolic acid as scaffold material, we molded a 3-dimensional scaffold for tissue engineering of human heart valves. The valve scaffold showed a deviation of only $\pm 3-4 \%$ in height, length and inner diameter compared with the homograft. The newly developed technique allows fabricating custom-made, patient-specific polymeric cardiovascular scaffolds for tissue engineering without requiring any suture materials.

Copyright $\odot 2008$ S. Karger AG, Basel
\end{abstract}

\section{Introduction}

Tissue engineering of heart valves represents a new experimental concept to fabricate viable and functional heart valve tissue from autologous cells. These tissue-engineered heart valve constructs theoretically have the potential to grow and to remodel which would be an important advantage especially for pediatric patients requiring heart valve replacement early in life. While tissue-engineered heart valves have successfully functioned in the pulmonary position in sheep, numerous issues need to be addressed before clinical application. For example, clinically feasible cell sources, the role of mechanical factors (e.g. bioreactor conditioning) and modified growth media for final human implantation have to be investigated. Furthermore, the design of a tissue-engineered heart valve is an important factor to fulfill the functional requirements of an implantable heart valve prosthesis [1-4].

To fabricate an implantable and functional heart valve, our laboratory focused on applying the principles of rapid prototyping in order to improve the design and the fabrication technique for tissue-engineered heart valve

\section{KARGER}

Fax +41613061234 E-Mail karger@karger.ch www.karger.com
P.K. Schaefermeier

Department of Cardiac Surgery, Laboratory for Tissue Engineering

University Hospital of the Ludwig-Maximilians-University

DE-81377 Munich (Germany)

Tel. +49 897095 4791, Fax +49 897095 3465, E-Mail pschaefe@med.lmu.de 

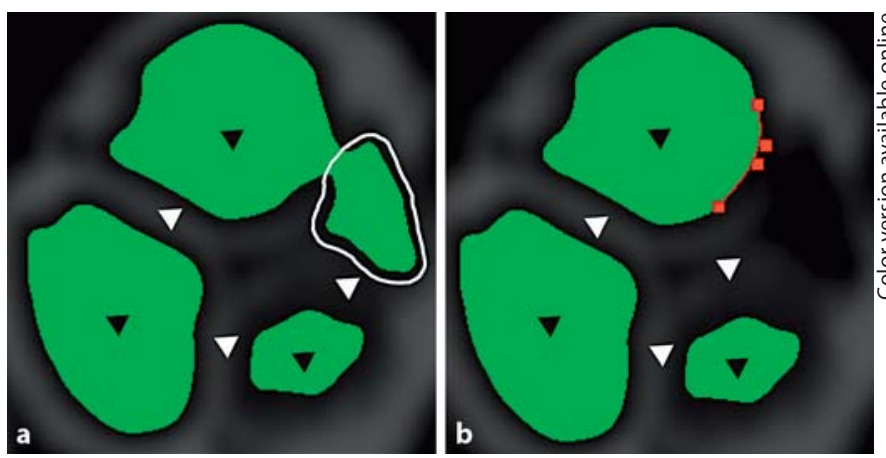

Fig. 1. a The segmented but unprocessed image of a heart valve derived from the CT scanning image. In comparison with the natural anatomical structure of the heart valve, there is an unexpected area being segmented (within the white circle) which does not represent the valve area. $\mathbf{b}$ With the help of the region-growing technique, the valve area was plotted out. Black triangles represent the area of the sinus of Valsalva (green areas in the online version); white triangles show the area of leaflets and commissures (black area).

scaffolds resembling the anatomy of a native human heart valve [5]. Currently we describe a fabrication technique to generate a 3-dimensional heart valve scaffold, which was designed in the shape of the natural aortic valve, to provide temporary mechanical support for the construction of a viable and surgically feasible human heart valve.

\section{Material and Methods}

\section{Prototyping Process}

An aortic homograft was used as a prototype to fabricate an individual heart valve scaffold with the correct anatomy of the human aortic valve. The homograft had not been accepted for heart surgery because of a positive microbiological test and was prepared for computed tomography (CT) scanning under the guideline of the laboratory for homografts at the German Heart Institute Berlin. We had previously introduced the idea of 3-dimensional reconstruction of heart valves. However, the prepared valve was scanned by CT at $2 \mathrm{~mm}$ slice distance and $0.1 \times 0.1 \mathrm{~mm}$ pixel size within all slices. The image data derived from CT were processed with our in-house software (Amira-Anaplast) which performs the image segmentation (border extraction with an appropriate density threshold). For specifying the region of valve location, the segmented images were further processed by a region-growing technique (fig. 1a, b). The 2-dimensional segmented images were interpolated from adjacent sections above and below to establish a visualized 3-dimensional aortic valve and root model. The 3-dimensional model was converted into a stereolithographic (STL) model and fed to the FDM 3000 stereolithography machine (Stratasys, Eden Prairie, Minn., USA) for construction of a resinic STL heart valve model. In addition, a nega- tive cast of the ventricular side of the aortic homograft was created to construct a subsequent heart valve scaffold.

\section{Scaffold Material}

A polymeric material was used for the fabrication of a heart valve scaffold. Poly-4-hydroxybutyrate (P4HB; MW 700,000 by gel permeation chromatography, porosity $80 \%$, pore size $80-240$ $\mu \mathrm{m}$, thickness $300 \mu \mathrm{m}$ ) is a biopolyester produced by a proprietary fermentation process (Tepha, Cambridge, Mass., USA). P4HB is a semicrystalline, thermoplastic elastomer with a melting point of approximately $60^{\circ} \mathrm{C}$ and a glass transition temperature of $-51^{\circ} \mathrm{C}$.

\section{Heart Valve Scaffold Fabrication}

The STL silicone model was then used to fabricate a polymeric heart valve. This consisted of 3 steps, as shown in figure 2. Firstly, a rectangular piece of the polymer is wrapped around the negative cast of the silicone STL model (ventricular side of the STL silicone model) and trimmed off the potential sinus of Valsalva to shape a stent-like scaffold [4]. In the following step, another piece of polymer is wrapped around the stent-like polymeric scaffold and is fixed by a thermal processing technique. The upper edges of the polymer are trimmed according to the shape of the 3 leaflets, gently pressed onto the negative cast and manually molded. The third step is to use a polymer patch to form the sinus of Valsalva and the vascular wall of a valved conduit. The whole heart valve scaffold is then placed at $4-8^{\circ} \mathrm{C}$ for $24-48 \mathrm{~h}$ for cooling to develop the stable and exact shape of the aortic heart valve and root. Thus, in the whole process we accurately imitate the structure of the native aortic heart valve and use the thermoplastic technique to fabricate the trileaflet heart valve scaffold using a biodegradable porous polymer.

\section{Bioreactor Testing}

The P4HB heart valve scaffold for tissue engineering was tested in a bioreactor pulsed by a simple respirator (dual-phase control ventilator; Harvard Apparatus, Holliston, Mass., USA), with inspiration/expiration set to $30 / 70$ and frequency to 50 strokes/ min. The testing device was completely transparent to facilitate observation of the function of the heart valve scaffold. The setup was connected to 2 sensor elements of a digital pressure monitoring device (Hellige Cardioserv, Freiburg, Germany), as described previously [5].

\section{Results}

\section{STL Model Construction}

Figure 1 shows the segmented but unprocessed CT scanning image of a heart valve by the region-growing technique. In comparison with the anatomy of a native heart valve, there is an unexpected area being segmented which does not represent the valve area (fig. la). With the help of the region-growing technique, the valve area is plotted out (fig. 1b). From the segmented images we reconstructed the 3-dimensional STL model (fig. 3). Based on the STL model, a silicone model with the exact valvular 
Fig. 2. Scaffold fabrication steps. (1) A rectangular film of composite polymer is wrapped around the negative silicone STL model, and the sinus of the scaffold is cut out. (2) Polymeric scaffold P4HB is wrapped around the stent-like scaffold to ultimately form the leaflets. The upper part of the silicone STL model will be gently pressed onto the polymeric scaffold (leaflets) in order to form the leaflets. (3) The polymeric conduit is wrapped around the whole valvular construct, and the characteristic sinus of Valsalva is formed by a thermal processing technique.
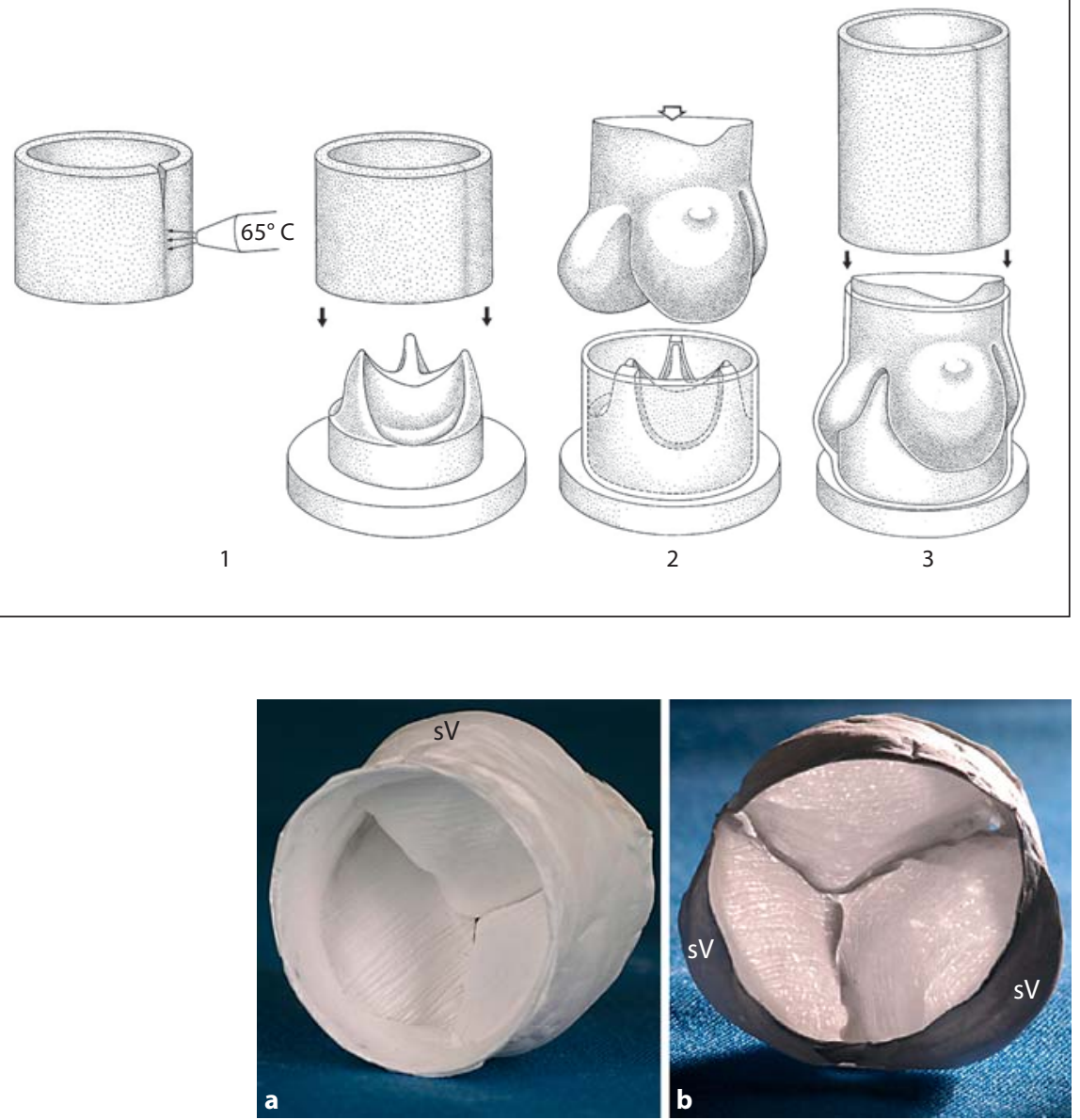

Fig. 4. a P4HB heart valve scaffold based on an STL model seen from the ventricular side. $\mathbf{b}$ Same model seen from the aortic side. $\mathrm{sV}=$ Sinus of Valsalva.

by molding porous $\mathrm{P} 4 \mathrm{HB}$ into the shape of a heart valve using the thermoplastic technique. This heart valve scaffold was fabricated without any suture materials or additional stent and resembled the natural complex anatomical structure of the human aortic heart valve. Measuring of the ventricular outer diameter of the newly created heart valve showed a length of $22.5 \mathrm{~mm}$ compared with $23.2 \mathrm{~mm}$ for the aortic homograft template. Height, length and inner diameter of the scaffold showed a deviation of $\pm 3-4 \%$.

\section{The Function of the Heart Valve Scaffold}

The constructed heart valve scaffold opened and closed synchronously in a pulsatile flow bioreactor under normal and supranormal flow and pressure conditions, 
Table 1. Direct pressure measurements ( $\mathrm{mm} \mathrm{Hg}$, means $\pm \mathrm{SD}$ ) of the heart valve scaffold

\begin{tabular}{|c|c|c|}
\hline \multirow{2}{*}{$\begin{array}{l}\text { Stroke } \\
\text { volume }\end{array}$} & \multicolumn{2}{|c|}{ Direct pressure measurements } \\
\hline & $\begin{array}{l}\text { distally to the heart } \\
\text { valve scaffold }\end{array}$ & $\begin{array}{l}\text { proximally to the heart } \\
\text { valve scaffold }\end{array}$ \\
\hline $10 \mathrm{ml}$ & $5.4 \pm 0.89$ & $8.60 \pm 0.54$ \\
\hline $25 \mathrm{ml}$ & $7.2 \pm 0.45$ & $8.60 \pm 0.54$ \\
\hline $50 \mathrm{ml}$ & $27.4 \pm 0.55$ & $29.80 \pm 0.83$ \\
\hline $100 \mathrm{ml}$ & $49.4 \pm 1.52$ & $52.20 \pm 0.84$ \\
\hline $200 \mathrm{ml}$ & $101 \pm 1.64$ & $102.80 \pm 0.84$ \\
\hline $300 \mathrm{ml}$ & $172 \pm 0.55$ & $171.60 \pm 1.14$ \\
\hline $400 \mathrm{ml}$ & $213 \pm 4.93$ & $211.40 \pm 1.14$ \\
\hline $500 \mathrm{ml}$ & $264 \pm 4.39$ & $264.20 \pm 4.66$ \\
\hline
\end{tabular}

with a maximum pressure gradient of $10 \mathrm{~mm} \mathrm{Hg}$ under systemic systolic pressure conditions. Only mild stenosis and regurgitation were observed in the heart valve scaffold (table 1).

\section{Discussion}

Valve replacement is the predominant treatment for end-stage valvular heart disease. Worldwide, up to 300,000 heart valves are replaced each year, the currently used prosthetic heart valves being either mechanical or biological [6]. Although mechanical valves exhibit excellent durability, they are thrombogenic and require lifelong anticoagulation therapy. Bioprosthetic heart valves as well as homografts have appropriate hemodynamic properties; but their limited durability, premature calcification, lack of growth potential and the intricate availability of donor organs restrict their application, especially in pediatric patients [7-9].

Tissue engineering of heart valves could overcome these disadvantages. The success of any therapy involving the transplantation of cells relies on the development of suitable substrates for both in vitro and in vivo tissue culture [10]. In our laboratory, we focused on using biodegradable polymers to shape regenerating heart valve tissue, provide temporary mechanical support and enhance tissue regeneration. Although tissue-engineered trileaflet heart valves based on synthetic biodegradable scaffolds have successfully functioned in the pulmonary circulation of sheep, the physiological valve scaffold geometry and fabrication remain a significant problem. In tissue engineering of functional implants such as heart valves, the initial shape of the biodegradable scaffold will guide the tissue development and is important for the final hemodynamic function of the newly created heart valve construct. Stock et al. [6] reported the use of a cylindrical valved conduit without any sinus of Valsalva and leaflets sutured to the conduit. Twenty-four weeks after implantation the authors described a thrombus formation in the area of the leaflet suture which limits the hemodynamic function of the newly created heart valve construct [6]. Based on this observation, we aim for a precise design combined with the avoidance of any sutures at the flow-exposed side to attain long-term function of the heart valve.

Furthermore it is the authors' opinion - in agreement with several specialists in the field - that an optimal valve design lowers the risk of design-related heart valve failure, the risk of suture-related thrombosis and inadequate tissue formation [9]. The development of a rapid prototyping technique has made it possible to reconstruct complex human valve structures. This rapid prototyping is defined as a group of techniques used to quickly fabricate the physical models of tissue scaffolds and custommade tissue implant prostheses based on the advanced development of computer-aided design/computer-aided manufacturing to generate a 3-dimensional anatomical model $[10,11]$. Stereolithography, as one of the rapid prototyping techniques, has already been used in craniomaxillofacial surgery and the construction of an aortic aneurysm model $[12,13]$. The accuracy and the ability to intimately control the overall macroscopic shape of the implants makes the rapid prototyping techniques an ideal process for fabricating implant and tissue engineering scaffolds.

The rapid prototyping technique of stereolithography was applied to physiologically design a heart valve scaffold which resembles the complex natural anatomical structure of a human aortic homograft using $\mathrm{P} 4 \mathrm{HB}$ as scaffold material. In our current experiment, a new technique was developed to fabricate a heart valve scaffold for tissue engineering. Moreover, the polymer was molded into the shape of a custom-made heart valve using the thermoplastic technique without requiring any suturing in the valve leaflet formation.

In this technical report we describe the detailed technical steps to fabricate a trileaflet heart valve scaffold including the sinus of Valsalva to ultimately develop a custom-made heart valve prosthesis. Although early results appear promising, the tissue engineering of heart valves is a developing area, and numerous issues need to be addressed. We do not believe that only the valve design 
leads to appropriate tissue formation, but physiological heart valve design is one significant factor in order to fabricate an autologous heart valve substitute. One of the important areas is the use of scaffold materials with a controllable degradation rate, appropriate mechanical properties, high plasticity and favorable biocompatibility for the cells to attach, proliferate, form a matrix and finally develop new and functional tissue for an advanced heart valve replacement. Our research aims to apply improved tissue engineering techniques to provide a patient-specific heart valve replacement for implantation.

\section{Acknowledgments}

This study was supported by a grant from the Bundesministerium für Bildung und Forschung (BMBF 01GN0544). P.F. was supported by the Deutsche Akademische Austauschdienst. We thank David P. Martin (Tepha Inc., Cambridge, Mass., USA) for his generous gifts of $\mathrm{P} 4 \mathrm{HB}$ and his advice concerning the polymeric scaffold. Furthermore, we thank Anne Gale (editing), Annette Gaussmann (graphics), Helge Haselbach (graphics), Uwe Teifel (graphics) and Reinhold Giering-Jensch (graphics) for their assistance in the preparation of the manuscript.

\section{References}

1 Langer R, Vacanti JP: Tissue engineering. Science 1993;260:920-926.

2 Shinoka T, Breuer CK, Tanel RE, Zund G, Miura T, Ma PX, Langer R, Vacanti JP, Mayer JE Jr: Tissue engineering heart valves: valve leaflet replacement study in a lamb model. Ann Thorac Surg 1995;60:S513S516.

3 Hoerstrup SP, Sodian R, Daebritz S, Wang J, Bacha EA, Martin DP, Moran AM, Guleserian KJ, Sperling JS, Kaushal S, Vacanti JP, Schoen FJ, Mayer JE Jr: Functional living trileaflet heart valves grown in vitro. Circulation 2000;102:III44-III49.

4 Sodian R, Hoerstrup SP, Sperling JS, Daebritz S, Martin DP, Moran AM, Kim BS, Schoen FJ, Vacanti JP, Mayer JE Jr: Early in vivo experience with tissue-engineered trileaflet heart valves. Circulation 2000;102: III22-III29.
5 Sodian R, Loebe M, Hein A, Martin DP, Hoerstrup SP, Potapov EV, Hausmann H, Lueth T, Hetzer R: Application of stereolithography for scaffold fabrication for tissue engineered heart valves. ASAIO J 2002;48: 12-16.

6 Stock UA, Nagashima M, Khalil PN, Nollert GD, Herden T, Sperling JS, Moran A, Lien J, Martin DP, Schoen FJ, Vacanti JP, Mayer JE Jr: Tissue-engineered valved conduits in the pulmonary circulation. J Thorac Cardiovasc Surg 2000;119:732-740.

7 Vongpatanasin W, Hillis LD, Lange RA: Prosthetic heart valves. N Engl J Med 1996; 33:407-416.

8 Jamieson WR: Modern cardiac valve devices - bioprostheses and mechanical prostheses: state of the art. J Card Surg 1993;8:8998

9 Schoen FJ, Levy RJ: Tissue heart valves: current challenges and future research perspectives. J Biomed Mater Res 1999;47:439-465.
10 Yang S, Leong KF, Du Z, Chua CK: The design of scaffolds for use in tissue engineering. 2. Rapid prototyping techniques. Tissue Eng 2002;8:1-11.

11 Sun W, Lal P: Recent development on computer aided tissue engineering - a review. Comput Methods Programs Biomed 2002; 67:85-103.

12 Lermusiaux P, Leroux C, Tasse JC, Castellani L, Martinez R: Aortic aneurysm: construction of a life-size model by rapid prototyping. Ann Vasc Surg 2001;15:131-135.

13 D'Urso PS, Barker TM, Earwaker WJ, Bruce LJ, Atkinson RL, Lanigan MW, Arvier JF, Effeney DJ: Stereolithographic biomodelling in cranio-maxillofacial surgery: a prospective trial. J Craniomaxillofac Surg 1999;27:3037. 